\title{
The National Estuarine Research Reserve System: A Review of Research and Monitoring Initiatives
}

\author{
Michael J. Kennish \\ Department of Marine and Coastal Sciences, Rutgers University, New Brunswick, New Jersey, USA \\ Email:kennish@marine.rutgers.edu
}

How to cite this paper: Kennish, M.J. (2019) The National Estuarine Research Reserve System: A Review of Research and Monitoring Initiatives. Open Journal of Ecology, 9, 50-65.

https://doi.org/10.4236/oje.2019.93006

Received: January 30, 2019

Accepted: March 18, 2019

Published: March 21, 2019

Copyright $\odot 2019$ by author(s) and Scientific Research Publishing Inc. This work is licensed under the Creative Commons Attribution International License (CC BY 4.0).

http://creativecommons.org/licenses/by/4.0/

\begin{abstract}
The National Estuarine Research Reserve System (NERRS) is an integrated network of 29 protected and coordinated estuarine reserve sites in 23 states and one territory (Puerto Rico) covering more than 525,000 ha of estuarine habitat, adjoining wetlands, and uplands that encompass 19 biogeographical regions along the Atlantic, Gulf of Mexico, and Pacific coasts, as well as the Caribbean Sea and Great Lakes. NERRS is an ecosystem-based research and monitoring network of sites serving as platforms to develop quantitative databases of value to coastal management programs in identifying and tracking short-term variability and long-term changes in the integrity and biodiversity of estuarine systems nationwide due to natural perturbations and anthropogenic disturbances. The reserve sites also play a vital role in assessing coastal issues of local, regional, and national significance for the purpose of sustaining estuarine systems and coastal lands, such as evaluating their responses to climate change and other major stressors to inform coastal decision-making and public awareness for the protection and resilience of natural resources and coastal communities. Over the past four decades, NERRS sites have collected large volumes of research and monitoring data of great utility in characterizing estuarine environments and addressing an array of resource-management concerns, including degraded water quality, loss and alteration of essential habitat, impacted fisheries, invasive species, and conservation.
\end{abstract}

\section{Keywords}

NERRS, Estuaries, System-Wide Monitoring Program, Integrated Research, Sentinel Sites, Climate Change

\section{Introduction}

The National Estuarine Research Reserve System (NERRS) is an integrated net- 
work of estuary reserve sites occurring in 19 biogeographical regions along the Atlantic, Gulf of Mexico, and Pacific coasts, as well as the Caribbean Sea and Great Lakes. NERRS provides cutting-edge research and monitoring initiatives, education programs, and outreach services to improve the management and stewardship of the nation's estuaries. It serves as a coordinated system for the detection and measurement of local, regional, and national trends in estuarine conditions. NERRS focuses on three strategic areas of importance to coastal communities: climate change, water quality, and habitat protection [1]-[7].

NERRS consists of a network of 29 reserve sites located in 23 states and Puerto Rico; collectively, they protect more than 525,000 ha of estuarine and coastal habitat for the purpose of long-term research, environmental monitoring, education, and coastal stewardship [7] (Figure 1). The reserve system consists of a partnership between NOAA and the coastal states and territories. The Office of Coastal Management at NOAA is the administrative lead for NERRS, providing funding, technical assistance, coordination, and guidance. Each reserve site is managed either by a university or state agency that promotes locally relevant,

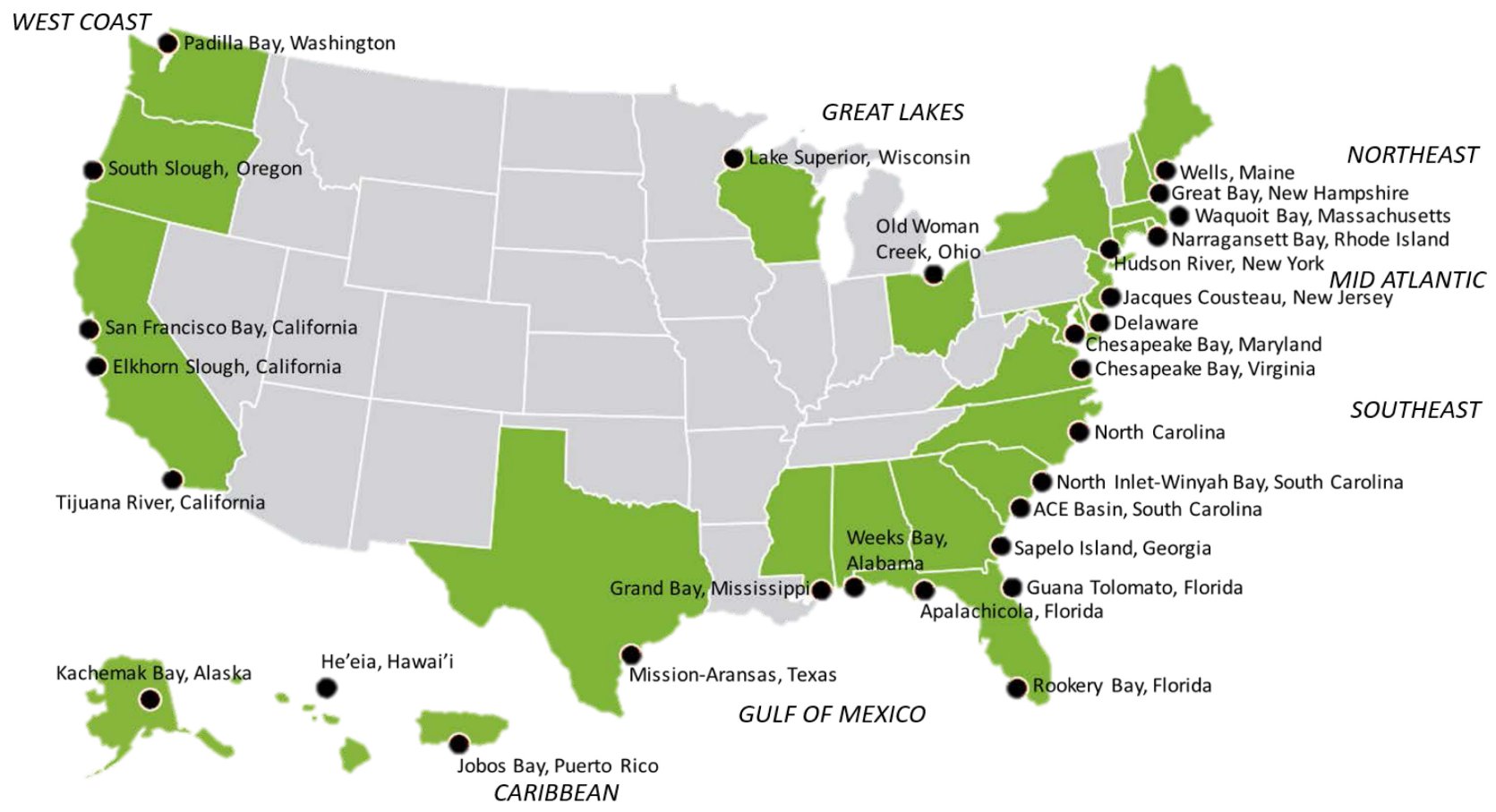

Figure 1. Map showing the location of 29 National Estuarine Research Reserve (NERR) program sites [Source: NOAA, National Estuarine Research Reserve, Silver Spring, Maryland]. These include the following: 1) Wells NERR, Maine; 2) Great Bay NERR, New Hampshire; 3) Waquoit Bay NERR, Massachusetts; 4) Narragansett Bay NERR, Rhode Island; 5) Hudson River NERR, New York; 6) Jacques Cousteau NERR, New Jersey; 7) Delaware NERR, Delaware; 8) Chesapeake Bay NERR, Maryland; 9) Chesapeake Bay NERR, Virginia; 10) North Carolina NERR, North Carolina; 11) North Inlet-Winyah Bay NERR, South Carolina; 12) Ashepoo Combahee Edisto Basin NERR, South Carolina; 13) Sapelo Island NERR, Georgia; 14) Guana Tolomato Matanzas NERR, Florida; 15) Rookery Bay NERR, Florida; 16) Apalachicola NERR, Florida; 17) Weeks Bay NERR, Alabama; 18) Grand Bay NERR, Mississippi; 19) Mission-Aransas NERR, Texas; 20) Tijuana River NERR, California; 21) Elkhorn Slough NERR, California; 22) San Francisco Bay NERR, California; 23) South Slough NERR, Oregon; 24) Padilla Bay NERR, Washington; 25) Lake Superior NERR, Wisconsin; 26) Old Woman Creek NERR, Ohio; 27) Jobos Bay NERR, Puerto Rico; 28) Kachemak Bay NERR, Alaska; 29) He'eia NERR, Hawaii. 
integrated approaches to coastal management, utilizing scientists, educators, stakeholders, and land management professionals to address pressing environmental issues of coastal communities. For example, the reserves assist coastal communities with technical support to prepare for, and to recover from, storm surge and flooding of hurricanes and other extreme weather events.

NERRS research and monitoring data are used to assess coastal issues of local, regional, and national importance for the purpose of sustaining estuarine systems [7] [8]. Monitoring is closely tied to process research at these sites to develop solutions to complex watershed, wetland, and aquatic system problems and to support effective coastal resource management. Thus, the reserve sites serve as ecosystem-based platforms of study to develop quantitative databases and to delineate changes in physical, chemical, and biological conditions and ecological processes of estuarine and coastal systems.

The standardization of sampling protocols, exemplified by NERRS' System-wide Monitoring Program (SWMP) enables accurate data comparisons among the reserve sites of value in assessing estuarine environmental trends of regional and national scale [9] [10]. While these sampling protocols are extremely useful for forging integrated studies across a network of reserve sites, individual reserves also have the capacity to pursue independent research and monitoring projects that address specific problems within their estuarine systems. The main goals of NERRS research and monitoring programs are: 1) ensuring a stable environment for research through long-term protection of reserve resources; 2) addressing coastal management issues through coordinated estuarine research and monitoring within the system; 3) collecting data necessary for improved understanding and management of estuarine areas; and 4) making the information available to coastal managers, stakeholders, and the general public [8] [9] [10] [11]. The output of these programs contributes to informed coastal decision-making and greater public awareness of the environmental importance of the nation's estuaries.

Many of these reserve sites are generally undisturbed areas that serve as reference locations for comparison with systems impacted by anthropogenic activities. Through its integrated programs, NERRS strives to enhance the management of estuarine resources. The mission of the reserve system is to "practice and promote stewardship of coasts and estuaries through innovative research, education, and training using a place-based system of protected areas [6]."

\section{NERRS Origin}

The Coastal Zone Management Act (CZMA) of 1972, as amended, established the NERRS program. In addition to providing base funding for administrative operations, research and monitoring, education, coastal training programs, and stewardship for NERRS, NOAA also sets operating standards of the reserves, supports activities at each reserve, and facilitates decision-making at the national level. A network of protected reserve areas serves as sentinel sites to better un- 
derstand how climate and other natural and anthropogenic drivers of change affect watersheds and coastal ecosystems. NERRS staff works with local communities, government agencies, academic institutions, and other partners to foster sound coastal resource management plans, targeting problematic elements such as nonpoint source pollution, land-use change, vulnerability of wetlands, habitat restoration, and coastal resilience. This effort is strengthened by interactive education, outreach, and stewardship programs that promote effective uses and sustainability of coastal resources. As summarized by Kennish [10], the NERRS program represents "... a federal, state, and community partnership in which research and monitoring, together with a comprehensive program of education and outreach, strengthen understanding, appreciation, and stewardship of estuaries, coastal habitats, and associated watersheds."

\section{NERRS Research and Monitoring Programs}

Four major objectives of NERRS research and monitoring programs are:

1) To monitor and assess changes in water quality and quantity, habitat, and biological indicators in response to land-use and climate change stressors.

2) To improve understanding of the effects of climate change and coastal pollution on estuarine and coastal ecology, ecosystem processes, and habitat structure and function.

3) To increase resilience of coastal systems to climate change impacts.

4) To support ecosystem-based management of natural and built communities by characterizing coastal watersheds and estuarine ecosystems and quantifying ecosystem services [4] [7].

NERRS relies on sustained long-term research and monitoring to identify patterns of change in natural communities and ecosystems and establish the causes of the observed changes. The NERRS monitoring program, coupled with supported research components, serves as a foundation for developing solutions to coastal management problems by determining how estuarine ecosystems change and why they change. A primary goal is to delineate the natural and anthropogenic processes governing stability and change, and in so doing, assist coastal resource managers in making informed decisions to remediate environmental impacts and restore conditions. Another important goal of NERRS is to increase public awareness of estuarine systems via its education and coastal training programs that stress the protection and sustainability of natural resources in the coastal zone.

As human settlements continue to grow in coastal areas, estuaries are exposed to increasing stressors from changing land use, increased pollutant loads, declining freshwater inflows, and changing climate. In order to devise effective measures necessary to minimize or mitigate the impact of human activities on estuarine biodiversity and productivity, high-quality environmental and biological databases are needed over the long term to inform coastal management decisions. NERRS is conducting regional and national data syntheses using data- 
bases compiled in its SWMP and Sentinel Site Programs to address management needs. This paper recounts the research and monitoring initiatives of NERRS that generate these important databases which are of value to local, regional, and national coastal management programs.

\subsection{System-Wide Monitoring Program (SWMP)}

NERRS established SWMP in 1995, and it now forms the cornerstone of its monitoring, research, and environmental assessment projects. SWMP is a coordinated, ecosystem-based monitoring network designed to identify and track short-term variability and long-term changes in the structure and function of reserve-site estuaries and their coastal watersheds [3] [12] [13]. Important program components are water-quality and meteorological monitoring, biomonitoring, and watershed, habitat, and land-use mapping. The compilation and analysis of monitoring data are useful for establishing baseline conditions and delineating trends for NERRS estuaries, assessing abiotic and biotic drivers of change at the ecosystem level, and comparing environmental conditions among the reserve sites. SWMP also provides a means of monitoring the impact of episodic extreme events, such as hurricanes and droughts. Investigation of climate change effects has become a focal point of SWMP in recent years.

SWMP is one of the most comprehensive and effective programs for monitoring the water-quality conditions of the nation's estuaries. It uses standardized sampling protocols for abiotic and biotic monitoring to generate data on national estuarine water-quality trends, while allowing the flexibility of reserve sites to assess watershed land-use and habitat change as well as other coastal management issues of local or regional concern. The standardization of sampling protocols facilitates data comparisons across reserve sites. As the SWMP databases increase through time, they are more useful for identifying changes in estuarine conditions, interpreting and predicting responses to change, and documenting anthropogenic stressors that may be addressed by coastal decision-makers. In addition, long-term SWMP databases afford greater understanding of how estuarine ecosystems function and change over time, thereby forming a foundation for devising sound solutions to coastal management problems.

YSI 6600 and EXO data sondes equipped with probe technologies collect a continuous array of estuarine water-quality data at fixed-location, SWMP sampling stations. The suite of environmental parameters monitored at these stations include water temperature, specific conductance, salinity, DO concentration, $\mathrm{DO}$ percent saturation, $\mathrm{pH}$, turbidity, and tidal variation (pressure/depth). The data sondes record parameter measurements in 15-minute increments year-round at the sampling stations. Two of these stations have telemetry equipment that broadcasts water-quality data to a GOES satellite, which is then posted to the World Wide Web. In addition, nutrient data are collected monthly via standard grab samples and an automated ISCO sampler at monitoring stations. Nutrient parameters measured at each reserve site since 2002 include at a 
minimum ammonium, nitrate + nitrite, orthophosphate, and chlorophyll a. Some reserve sites collect data on other nutrient parameters as well.

Meteorological data are also collected at each reserve site using a Campbell weather station that continuously records air temperature, wind speed and direction, solar radiation, barometric pressure, humidity, photosynthetically-active radiation, and precipitation. These data enable investigators to determine how estuarine water quality in the NERRS program varies in response to changes in meteorological conditions. Biomonitoring is conducted at multiple reserve sites, primarily targeting tidal marshes, seagrasses, and mangroves [14]. Data are collected on plant community composition, species diversity, density, distribution, canopy height, and areal cover. Additional parameters, such as plant biomass, are also measured by some reserve sites. Biomonitoring often extends to other biotic groups as well, including plankton, nekton, benthos, and avifauna.

Water-quality, meteorological, and biomonitoring data derived from all reserve sites are stored in a repository at the Centralized Data Management Office (CDMO) at the Belle W. Baruch Institute for Marine and Coastal Sciences of the University of South Carolina. The CDMO serves as the SWMP databank, archiving and analyzing monitoring data and information products from each reserve site, and supporting the exchange of data and metadata within the system of reserve sites. In addition, it serves a critical role in quality control of SWMP data for the NERRS program. In addition, the CDMO oversees the management, documentation, and publication of the NERRS monitoring data on the Internet. These databases, which are readily accessible, have been useful to researchers investigating variations in environmental conditions of the reserve estuaries locally, regionally, and across biogeographical regions.

In regard to biomonitoring, tidal wetlands and submersed vegetation communities are the primary targets for enhancement of the SWMP program. A major goal is to assess the effects of climate change, especially sea-level rise, as well as anthropogenic factors on the biotic integrity of wetland systems at the reserve sites. What will be the response in terms of spatial distribution and community composition of coastal marshes, mangroves, and seagrass beds to long-term changes in water levels and inundation? The main objectives of monitoring emergent and submersed vegetation communities are:

1) To quantify vegetation patterns (community composition, species abundance, and distribution) and their change over space and time.

2) To supply detailed information that can be used to support comprehensive remotely-sensed mapping of vegetation communities, field surveys, and other NERRS SWMP data collection, as well as NERRS/NOAA education, stewardship, and restoration efforts.

3) To establish a foundation for quantifying relationships among the various edaphic factors and the processes which regulate the patterns of distribution and abundance of organisms in the wetland communities.

4) To monitor conditions consistently over a wide range of estuarine sites and habitats, and for a variety of reserve specific purposes. 
5) To apply monitoring protocols used nationally and worldwide [14].

The biomonitoring field approach consists of establishing fixed transects (with 10 permanent sampling stations located along each transect) that can be stratified, if necessary, within vegetation zones or segments of the marsh or submersed vegetation beds [15] (Figure 2). The vegetation survey data are complemented with measures of marsh elevation changes using Surface Elevation Tables (SETs) at each reserve site. This approach has been used in a variety of studies for assessments of vegetation communities and has been recently adapted as a monitoring protocol by the National Park Service and others to assess and compare both reference and restoration wetland sites on local and regional scales. Additionally, similar protocols have been established for quantification of seagrass dynamics in a global seagrass monitoring program (http://www.SeagrassNet.org). To facilitate the understanding of sea-level rise

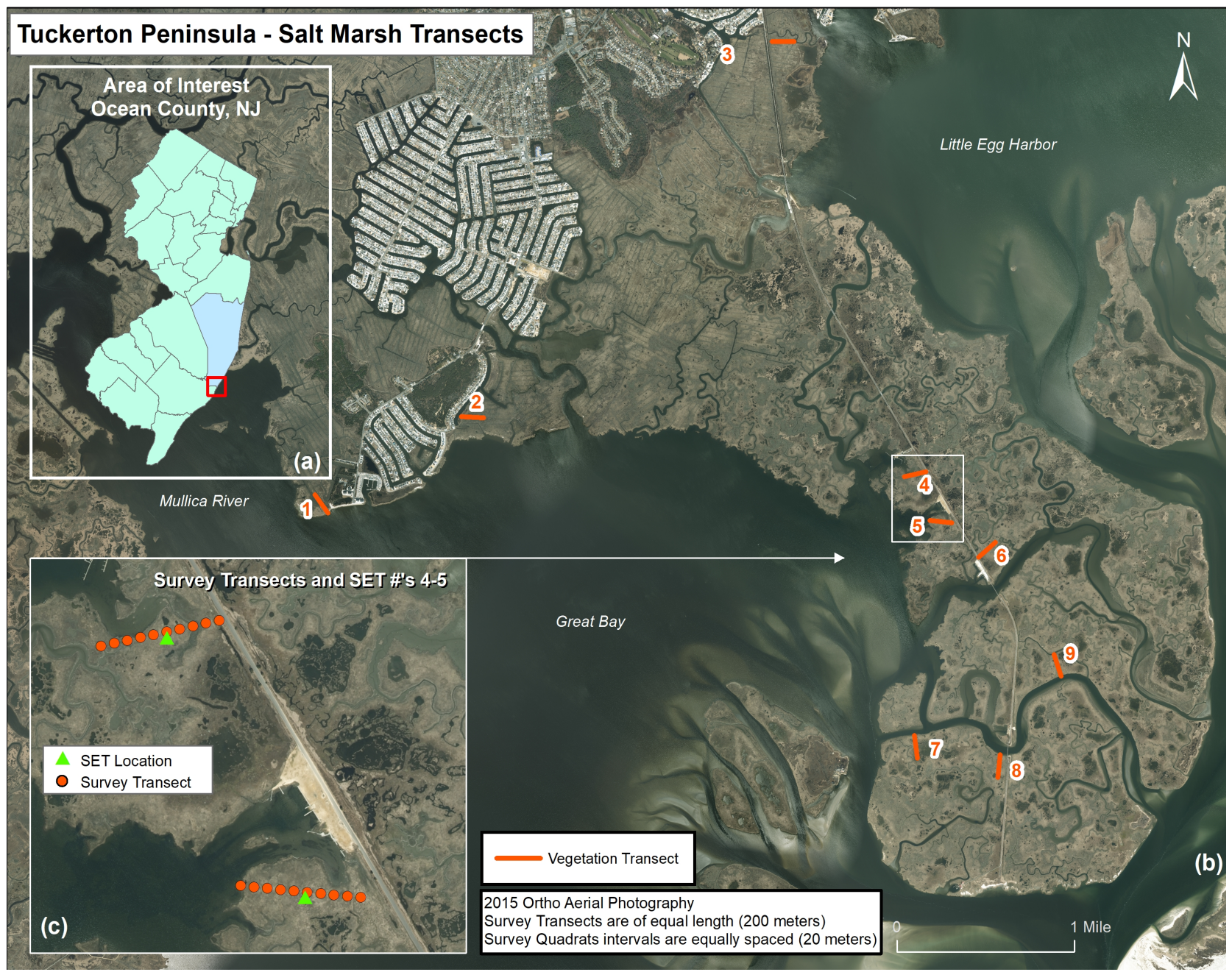

Figure 2. Map of the Tuckerton Peninsula salt marsh system which serves as the sentinel site of the Jacques Cousteau National Estuarine Research Reserve, Tuckerton, New Jersey. (a) Inset showing the location of the sentinel site with respect to the State of New Jersey. (b) 2000 ha Spartina-dominated salt marsh system showing the location of nine biomonitoring sampling transects in three segments of the study area (north, central, and south segments). (c) Enlarged central segment showing the location of biomonitoring transects 4 and 5 and the 10 sampling stations along the transects [11]. 
effects on marsh vegetation, NERRS is also developing vertical control plans to establish tidal and sea-level datums, measuring changes in sea level, and generating models to assess ecosystem impacts [5] [16]. High-resolution, Real-Time Kinetic (RTK) GPS surveying and LiDAR mapping are used as well to assess vegetation distribution and elevations.

SWMP water-quality, biomonitoring, and research data have been used in a wide array of research and management applications such as:

1) Improving the understanding of estuarine circulation.

2) Examining dissolved oxygen depletion in estuaries and coastal lagoons.

3) Assessing eutrophication.

4) Informing policy that sets numeric nitrogen and phosphorus criteria and establishes Total Maximum Daily Loads (TMDLs) for nitrogen and phosphorus.

5) Measuring light transmission through the water column to develop and implement water-clarity standards.

6) Characterizing water quality and biotic responses.

7) Documenting HAB bloom intensity and duration.

8) Investigating spatial and temporal changes in seagrass, salt marsh, and mangrove habitats.

9) Establishing salt marsh and seagrass habitat condition for long-term management of coastal zone resiliency.

10) Delineating landward migration of the wetland-upland boundary.

11) Tracking the impacts of hurricanes and other coastal storms to inform coastal managers of future storm impact vulnerability and adaptive planning.

12) Contributing to finfish and mariculture studies that are of value to fisheries management programs.

13) Evaluating drivers of shellfish growth and mortality.

14) Identifying invasive species.

15) Conducting habitat restoration.

Many priority research projects are conducted in NERRS that accompany SWMP water-quality monitoring and biomonitoring. These include examination of phytoplankton and zooplankton dynamics, characterization of benthic habitat and communities, restoration of shellfish and finfish populations, assessment of nutrient loading and estuarine eutrophication, demographic analysis of submersed aquatic vegetation, delineation of salt marsh structure and function, and the mapping of watersheds. Although not all of these projects are being conducted concurrently across the reserve sites, most are part of an ongoing research and monitoring plan to advance NERRS mission [17]-[22].

\subsection{Land Use, Land Cover, and Habitat Characterization}

The land-use and habitat characterization component of NERRS tracks the magnitude and extent of estuarine habitat change, and it leads to greater understanding of how these changes are linked to watershed land-use practices. U.S. coastal wetlands lose more than 200,000 ha of area each year due to development 
and other human activities, salt water intrusion, and inundation [7]. To track land-use and habitat change, a set of two standard monitoring procedures is applied at relevant scales that encompass each reserve and its surrounding watershed. Through a partnership with NOAA's Coastal Services Center, land cover in each reserve's watershed is characterized at moderate resolution (30-m) using data and protocols associated with the Coastal Change Analysis Program (C-CAP). These products are developed using remotely sensed imagery from which coastal intertidal areas, wetlands, and adjacent uplands are inventoried. Current inventories are maintained, and change analyses are conducted, by updating the land-cover maps at five-year intervals [6] [7].

Fine-scale, high-resolution habitat mapping and change analyses are conducted within each reserve's boundaries using a standardized classification scheme that incorporates habitat types as well as land-use types. This classification structure organizes habitats by their salinity zone, flooding regime, substrate type, and vegetation cover to yield very detailed inventories of resources within each reserve. In most reserves, data for this characterization are derived from aerial photographs or other high-resolution, remotely-sensed images. Extensive ground-truthing ensures a high degree of classification accuracy to support sensitive change analyses and trend assessments over time.

This work enables a comparison of local, regional, and national differences in watershed land-use patterns, an understanding of how these differences influence estuarine habitat quality, and an assessment of the sensitivity of specific habitat types given land-use change patterns. At local levels, this information is of value for effective coastal land-use planning and decision-making. It also provides critical data needed to assess specific issues, such as the risk posed to coastal habitats by sea-level rise.

\subsection{Climate Change and Sentinel Sites}

NERRS complements its long-term environmental monitoring efforts-on water quality and meteorological conditions, biomonitoring, and habitat and land use change-with initiatives to understand the impacts of climate change and anthropogenic stressors on human and estuarine ecosystem communities, vulnerability of these communities, and their capacity for adaptation and change. It is making a strong commitment to invest expertise and resources to better understand the impacts of climate change and vulnerabilities of estuaries and built communities, adaptation to these changes, and mitigation of impacts through greenhouse gas reduction and carbon sequestration. A priority strategy of NERRS is the implementation of research and monitoring programs that use reserves as sentinel sites for detecting and assessing the effects of sea-level rise and other climate change effects on estuaries [6] [7] [11] (Figure 3). To this end, NERRS is establishing sentinel sites at its reserve locations to facilitate these investigations [5].

Sentinel sites are components of a reserve that have the operational capacity 


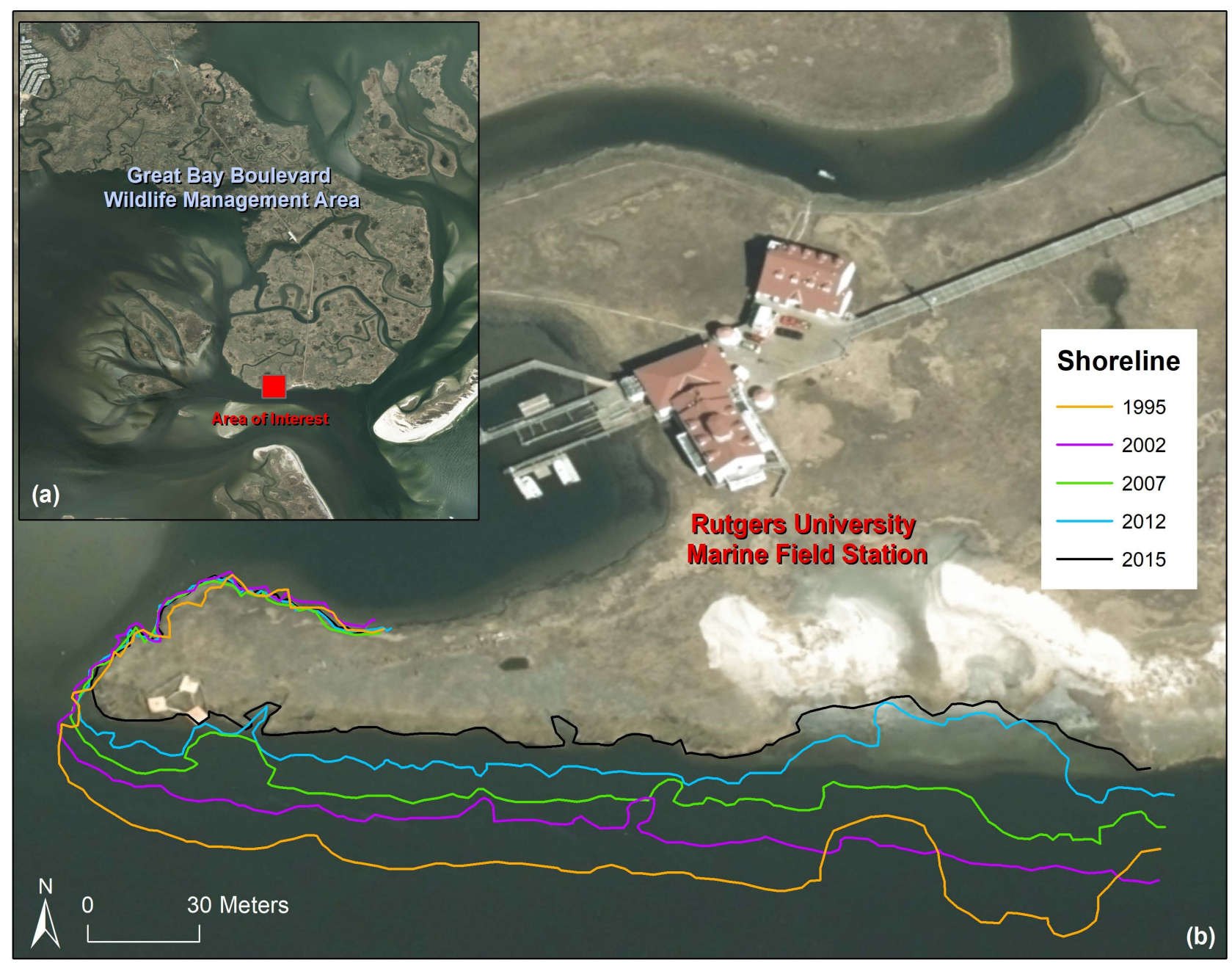

Figure 3. Southern shoreline of the Tuckerton Peninsula salt marsh system showing its continuous retreat in the face of rising sea level and shoreline erosion over the 20-year period from 1995 to 2015. (a) Inset showing the location of the study area with respect to the State of New Jersey. (b) Shoreline retreat along the southern shoreline in proximity to the Rutgers University Marine Field Station [11].

for intensive study and sustained observations to detect and understand the physical and biological changes in the ecosystems they represent [16] [23] [24] [25]. They not only serve as platforms for monitoring and research to detect and assess ecosystem shifts due to drivers of change in the coastal zone but also constitute reference sites for restoration projects that enhance habitat conditions. More extensive sentinel site networks are being developed by NERRS; a sentinel site network is a group of linked NERRS sentinel sites whose integrated data and information streams result in a broader understanding of ecosystem conditions at temporal and spatial scales relevant to local, regional, or national science and management priorities [24] [25].

The acquisition of sentinel-site research and monitoring data is useful for forging climate adaptation and mitigation plans for coastal communities. Habitat and vertical control data collected at the NERRS sentinel sites are made available to decision-makers in coastal states, thereby enabling them to deter- 
mine how the loss of natural habitat, such as salt marshes and mangroves, will affect coastal communities (e.g., via increased inland flooding, erosion, and water-quality changes), their adaptation to future habitat loss, and the development of mitigation plans and adaptation measures to address impacts. All of these data are vital to long-term resiliency of coastal states, particularly in the aftermath of the sweeping coastal destruction from high-impact hurricanes, such as Katrina, Sandy, and Harvey.

Climate forecasting models indicate that there will be increasing frequency and severity of damaging storms, storm surges, and flooding of coastal environments as global temperatures rise during the 21st century [26]. Other probable climate change impacts to reserve ecosystems identified by the NERRS program include changes in sea level, inundation, shoreline erosion and migration, hydrology, water quality and quantity, salt marsh extent, and invasive species. Rising sea level will exacerbate coastal storm effects.

Coastal inundation and the loss of coastal wetlands will render local coastal communities and their infrastructure more vulnerable to nuisance flooding and other extreme events as well. These impacts will be exacerbated by human development along the coast. With current sea-level rise amounting to $\sim 3-4$ $\mathrm{mm} \cdot \mathrm{yr}^{-1}$ in many areas of the U.S., coastal marsh surfaces and other habitat must continue to vertically aggrade to keep pace with the increasing water levels. According to the Fifth Assessment Report of the IPCC [26], global sea level is projected to rise 28 to $98 \mathrm{~cm}$ by 2100 , which will lead to significant inundation and loss of coastal habitat. In addition, there are many coastal areas that are subsiding due to compaction and isostatic adjustment, such as in the mid-Atlantic region, which will add considerably to relative sea-level rise. In New Jersey, a 1 to $1.2-\mathrm{m}$ rise in sea level by 2100 would result in the loss of about $3 \%$ of the land area of the state and $30 \%$ of the coastal marshlands [16]. This will have serious consequences for the state's coastal infrastructure and coastal real estate values. In addition, flooding will be more common. A "100-year" storm causes a surge of $\sim 2.5 \mathrm{~m}$. By 2100 , such surges could recur annually, flooding access to bridges, tunnels, and some upland areas in the process.

Greater upstream penetration of seawater would also increase the probability of damage to coastal vegetation and salt water intrusion into ground water supplies. Current land-cover and land-use modifications in coastal watersheds could contribute significantly to future infrastructure degradation by facilitating sea-level rise impacts via the removal of natural vegetative cover that now forms protective buffer against flooding. Salt water intrusion into ground water supplies and the loss of coastal vegetation would compromise property values in the coastal zone.

In sum, NERRS sentinel sites are ideal locations for assessing the vulnerability, integrity, and resilience of coastal wetland systems and their potential to buffer human settlements against coastal hazards, such as hurricanes, storm surge, and rising sea levels, thereby strengthening the long-term sustainability of the coastal 
zone. In advancing green infrastructure (e.g., healthy wetlands) as a coastal protection strategy, it is necessary to determine the longevity of these critical habitats in the face of continued, if not accelerated, coastal storms, sea-level rise, and coastal subsidence. The sustainability of these vital ecosystems must be understood in light of the fact that they are not spatially fixed but rather are dynamic, continually responding and shifting in response to these drivers of change.

An important management goal is to provide community administrators with accurate information needed to make effective decisions concerning the maintenance and restoration of wetlands bordering coastal communities. This information may derive in part from remotely-sensed and in-situ monitoring data and imagery to characterize wetland condition, mapping sea-level rise scenarios, and modeling expected changes in coastal habitat. The economic cost of maintaining coastal wetlands with future climate changes and long-term rising sea levels must also be considered.

The value of NERRS collaborative research and monitoring efforts is exemplified by applications underway at its sentinel sites [27] [28] [29] [30]. During the past several years, for example, NERRS has developed and implemented an innovative approach to understand how and why changing water levels and inundation due to climate change and other factors, are impacting tidal marshes and other coastal habitats. This approach titled "Sentinel Site Application Module 1 (SSAM-1)," is being used to assess coastal habitat response to water-level changes at multiple NERRS sentinel sites [25] [29]. To this end, more than 20 reserves are now applying consistent sampling protocols to relate wetlands vegetation data and water levels to a common vertical reference system. SSAM-1 data and products can help local resource managers and coastal communities to understand the vulnerability of representative reserve resources to climate change and to evaluate potential strategies for adaptation. These data and ancillary products are also being incorporated into K-12 schools and other education programs, providing examples of climate change science at work in school systems. At a national scale, SSAM-1 data syntheses, such as the "marsh sustainability report card," are currently being developed to highlight overall resilience of coastal vegetation in the face of water-level changes and to identify coastal areas at greatest risk.

SSAM-1 assessment uses multiple complementary metrics within six categories that can be individually scored and then averaged to calculate one final sustainability score for a coastal marsh system at NERRS sites. Current metric measurements in SSAM-1 yield data on marsh elevation distribution and change over time, sediment accretion and availability, tidal range, and sea-level rise that yield a marsh sustainability value useful for comparison across NERRS sites [25] [29]. Of the array of metric categories used in SSAM-1, marsh elevation change appears to be the most important indicator of marsh sustainability.

Raposa et al. [28] [29] [30] noted the importance of NERRS reserves as reference sites for assessing tidal wetlands and their restoration. As protected reference sites, NERRS wetlands can serve as ideal targets for restoration and for as- 
sessing resilience to sea-level rise and various anthropogenic stressors. This work can be extended to other estuarine subsystems, such as seagrass and shellfish beds.

\section{Conclusions}

The Coastal Zone Management Act of 1972 established the NERRS program, which is a network of 29 estuary reserve sites protecting more than 525,000 ha of estuarine and coastal habitats in the U.S. It is a national program that strives to enhance the management of estuarine resources by acting as a coordinated network for the detection and measurement of local, regional, and national trends in estuarine conditions. The mission of NERRS is to practice and promote stewardship of estuaries and coasts through innovative research, education, outreach, and training using a place-based system of protected areas to effectively address coastal management issues of concern. Three focus areas of NERRS research and monitoring are climate change, water quality, and habitat protection. Restoration science is also a priority of NERRS.

NERRS reserves are essentially demonstration areas where monitoring and research data are used to assess coastal issues of local, regional, and national interest for the purpose of sustaining estuarine systems. Considerable variation exists among the reserves, with site estuaries ranging from relatively pristine to impacted by anthropogenic activity. A major goal of the NERRS program is to ensure a stable environment for research at the reserve sites through long-term protection of resources. Aside from addressing estuarine resource protection issues, NERRS generates and disseminates comprehensive environmental databases via system-wide water quality monitoring and instruction within the coastal training program. NERRS also promotes increased public awareness of the importance of estuarine systems employing community outreach programs. Through these elements, NERRS serves as a vehicle to improve the health of the nation's estuarine and coastal environments.

SWMP is the major focus of NERRS research and monitoring initiatives. It addresses estuarine variability associated with both natural processes and anthropogenic activities through measurements of short-term variability and long-term changes in water quality, biotic community structure, aquatic habitat characteristics, and watershed land use and land cover at estuarine reserve sites. Since their inception, NERRS long-term monitoring and iterative habitat assessments have resulted in comprehensive databases for multiple purposes. Monitoring data serve as a basis for research to enhance fundamental understandings of the temporal and spatial dynamics of estuarine processes. In addition, the data provide management-relevant information to evaluate changes in estuarine ecosystems in response to natural perturbations and anthropogenic disturbances. Continued long-term monitoring efforts will yield valuable data to inform user groups and coastal resource managers of the cumulative effects of environmental stressors on estuarine ecosystems. 


\section{Acknowledgements}

Support for this work by the National Estuarine Research Reserve Program and Jacques Cousteau National Estuarine Research Reserve is gratefully acknowledged. This is Contribution Number 4168 of the Department of Marine and Coastal Sciences, Rutgers University, New Brunswick, New Jersey.

\section{Conflicts of Interest}

The author declares no conflicts of interest regarding the publication of this paper.

\section{References}

[1] Kennish, M.J. (2000) Estuary Restoration and Maintenance: The National Estuary Program. CRC Press, Boca Raton.

[2] National Estuarine Research Reserve System (2006) National Estuarine Research Reserve System: Research and Monitoring Plan (2006-2011). Estuarine Reserves Division, NOAA, Silver Spring.

[3] National Estuarine Research Reserve System (2007) The National Estuarine Research Reserve's System-Wide Monitoring Program (SWMP): A Scientific Framework and Plan Detection of Short-Term Variability and Long-Term Change in Estuaries and Coastal Habitats of the United States. Estuarine Reserves Division, NOAA, Silver Spring.

[4] National Estuarine Research Reserve System (2011) National Estuarine Research Reserve Strategic Plan 2011-2016. NOAA, Office of Ocean and Coastal Resource Management, Silver Spring.

[5] National Estuarine Research Reserve System (NERRS) (2012) Sentinel Sites Program Guidance for Climate Change Impacts. NOAA, Office of Ocean and Coastal Resource Management, Silver Spring.

[6] National Estuarine Research Reserve System (2012) National Estuarine Research Reserve System Research and Monitoring Plan 2012-2017. NOAA, National Estuarine Reserve System, Office of Ocean and Coastal Resource Management, Silver Spring.

[7] National Estuarine Research Reserve System (2017) National Estuarine Research Reserve Strategic Plan 2017-2022. NOAA, Office of Coastal Management, Silver Spring.

[8] Mills, K., Kennish, M.J. and Moore, K.A. (2008) Research and Monitoring Components of the National Estuarine Research Reserve System. Journal of Coastal Research, 66, 1-8. https://doi.org/10.2112/SI55-012.1

[9] Kennish, M.J. (2004) NERRS Research and Monitoring Initiative. Journal of Coastal Research, No. 45, 1-8. https://doi.org/10.2112/SI45-001.1

[10] Kennish, M.J. (2008) Research and Monitoring in a Nationally Integrated Network of NERRS Sites: Concluding Comments. Journal of Coastal Research, No. 55, 236-239. https://doi.org/10.2112/SI55-006.1

[11] Kennish, M.J., Lathrop, R.G., Spahn, A., Sakowicz, G.P. and Sacatelli, R. (2016) The JCNERR Sentinel Site: Research and Monitoring Applications. Bulletin of the New Jersey Academy of Science, 61, 1-8.

[12] Wenner, E.L., Holland, A.F., Arendt, M.D., Chen, Y., Edwards, D., Miller, C., et al. (2001) A Synthesis of Water Quality Data from the National Estuarine Research 
Reserve's System-Wide Monitoring Program. The Cooperative Institute for Coastal and Estuarine Environmental Technology, South Carolina Department of Natural Resources, Marine Resources Division, Charleston.

[13] Sanger, D.M., Arendt, M.D., Chen, Y., Wenner, E.L., Holland, A.F., Edwards, D., et al. (2002) Synthesis of Water Quality Data: National Estuarine Research Reserve System-Wide Monitoring Program (1995-2000). NOAA, National Estuarine Research Reserve System, Technical Report Series 3, Silver Spring.

[14] Moore, K. (2013) NERRS SWMP Biomonitoring Protocol: Long-Term Monitoring of Estuarine Submersed and Emergent Vegetation Communities. NOAA, National Estuarine Research Reserve System, Silver Spring.

[15] National Estuarine Research Reserve System (2001) Submerged Aquatic Vegetation: Data Development and Applied Uses CD-ROM. NOAA, Coastal Services Center, Charleston.

[16] Kennish, M.J., Spahn, A. and Sakowicz, G.P. (2014) Sentinel Site Development of a Major Salt Marsh System in the Mid-Atlantic Region. Open Journal of Ecology, 4, 77-86. https://doi.org/10.4236/oje.2014.43010

[17] Kennish, M.J., Bricker, S.B., Dennison, W.C., Glibert, P.M., Livingston, R.J., Moore, K.A., et al. (2007) Barnegat Bay-Little Egg Harbor Estuary: Case Study of a Highly Eutrophic Coastal Bay System. Ecological Applications, 17, S3-S16. https://doi.org/10.1890/05-0800.1

[18] Kennish, M.J., Haag, S.M. and Sakowicz, G.P. (2008) Seagrass Demographic and Spatial Habitat Characterization in Little Egg Harbor, New Jersey, Using Fixed Transects. Journal of Coastal Research, No. 55, 148-170. https://doi.org/10.2112/SI55-0013.1

[19] Kennish, M.J. and Fertig, B.M. (2012) Application and Assessment of a Nutrient Pollution Indicator Using Eelgrass (Zostera marina L.) in Barnegat Bay-Little Egg Harbor Estuary, New Jersey. Aquatic Botany, 96, 23-30.

https://doi.org/10.1016/j.aquabot.2011.09.005

[20] Fertig, B.M., Kennish, M.J. and Sakowicz, G.P. (2013) Changing Eelgrass (Zostera marina L.) Characteristics in a Highly Eutrophic Temperate Coastal Lagoon. Aquatic Botany, 104, 70-79. https://doi.org/10.1016/j.aquabot.2012.09.004

[21] Fertig, B., Kennish, M.J., Sakowicz, G.P. and Reynolds, L.K. (2014) Mind the Data Gap: Identifying and Assessing Drivers of Changing Eutrophication Condition. Estuaries and Coasts, 37, S198-S221. https://doi.org/10.1007/s12237-013-9746-5

[22] Lathrop, R.G., Haag, S.M., Merchant, D., Kennish, M.J. and Fertig, B. (2014) Comparison of Remotely-Sensed Surveys vs. in Situ Plot-Based Assessments of Sea Grass Condition in Barnegat Bay-Little Egg Harbor, New Jersey USA. Journal of Coastal Conservation, 18, 299-308. https://doi.org/10.1007/s11852-014-0319-y

[23] Kennish, M.J., Meixler, M.S., Petruzzelli, G. and Fertig, B. (2014) Tuckerton Peninsula Salt Marsh System: A Sentinel Site for Assessing Climate Change Effects. Bulletin of the New Jersey Academy of Science, 59, 1-5.

[24] NOAA (2011) NOAA Sentinel Site Program. NOAA, National Ocean Service, Silver Spring.

[25] National Estuarine Research Reserve System (2016) Coastal Habitat Response to Changing Water Levels: NERR Sentinel Site Application Module 1. NOAA, Office of Coastal Management, Silver Spring.

[26] Intergovernmental Panel on Climate Change (2014) IPCC Fifth Assessment Report. Cambridge University Press, Cambridge. 
[27] Meixler, M.S., Kennish, M.J. and Crowley, K.F. (2018) Assessment of Plant Community Characteristics in Natural and Human-Altered Coastal Marsh Ecosystems. Estuaries and Coasts, 41, 52-64. https://doi.org/10.1007/s12237-017-0296-0

[28] Raposa, K.B., Weber, R.L., Ekberg, M.C. and Ferguson, W. (2017) Vegetation Dynamics in Rhode Island Salt Marshes during a Period of Accelerating Sea Level Rise and Extreme Sea Level Events. Estuaries and Coasts, 40, 640-650.

https://doi.org/10.1007/s12237-015-0018-4

[29] Raposa, K.B., Wasson, K., Smith, E., Crooks, J.A., Delgado, P., Fernald, S.H., et al. (2016) Assessing Tidal Marsh Resilience to Sea-Level Rise at Broad Geographic Scales with Multimetric Indices. Biological Conservation, 204, 263-275.

https://doi.org/10.1016/j.biocon.2016.10.015

[30] Raposa, K.B., Lerberg, S., Cornu, C., Fear, J., Garfield, N., Peter, C., et al. (2018) Evaluating Tidal Wetland Restoration Performance Using National Estuarine Research Reserve System Reference Sites and the Restoration Performance Index (RPI). Estuaries and Coasts, 41, 36-41. https://doi.org/10.1007/s12237-017-0220-7 